ORIGINAL ARTICLE

\title{
Cancer incidence in airline cabin crew: experience from Sweden
}

\author{
A Linnersjö, N Hammar, B-G Dammström, M Johansson, H Eliasch
}

Occup Environ Med 2003;60:810-814

See end of article for authors' affiliations

......................

Correspondence to: A Linnersiö, Department of Epidemiology, Norrbacka, 17176 Stockholm, Sweden; anette.linnersjo@imm.ki.se

Accepted 11 October 2002

\begin{abstract}
Aims: To determine the cancer incidence in Swedish cabin crew.
Methods: Cancer incidence of cabin crew at the Swedish Scandinavian Airline System (SAS) (2324 women and 632 men) employed from 1957 to 1994 was determined during 1961-96 from the Swedish National Cancer Register. The cancer incidence in cabin crew was compared with that of the general Swedish population by comparing observed and expected number of cases through standardised incidence ratios (SIR). A nested case-control study was performed, including cancer cases diagnosed after 1979 and four controls per case matched by gender, age, and calendar year.

Results: The SIR for cancer overall was 1.01 (95\% Cl 0.78 to 1.24$)$ for women and $1.16195 \% \mathrm{Cl} 0.76$ to 1.55) for men. Both men and women had an increased incidence of malignant melanoma of the skin (SIR 2.18 and 3.66 respectively) and men of non-melanoma skin cancer (SIR 4.42). Female cabin attendants had a non-significant increase of breast cancer (SIR 1.30; $95 \% \mathrm{Cl} 0.85$ to 1.74). No clear associations were found between length of employment or cumulative block hours and cancer incidence.

Conclusions: Swedish cabin crew had an overall cancer incidence similar to that of the general population. An increased incidence of malignant melanoma and non-melanoma skin cancer may be associated with exposure to UV radiation, either at work or outside work. An increased risk of breast cancer in female cabin crew is consistent with our results and may in part be due to differences in reproductive history.
\end{abstract}

$\mathrm{D}$ uring recent years several studies have reported an excess risk of breast cancer for female cabin attendants. The first report came from Finland, showing a standardised incidence ratio (SIR) of 1.9 for breast cancer incidence. ${ }^{1}$ After this study similar findings were described for Danish cabin attendants ${ }^{2}$ and for retired air hostesses in the USA. ${ }^{3}$ Recently, an excess risk of breast cancer was reported from Iceland ${ }^{4}$ and from the United States, ${ }^{5}$ but in a study from Norway no excess breast cancer risk was observed. ${ }^{6}$ Several hypotheses have been discussed regarding the causes of an excess of breast cancer for cabin attendants, including occupational exposure to cosmic ionising radiation and low frequency electromagnetic fields. High altitude flights involve an increased exposure to cosmic ionising radiation where the level of exposure is dependent on altitude, flight route, flight duration, and solar activity. It has been suggested that commercial aircraft personnel may be receiving yearly doses in the order of 3-6 milliSieverts $(\mathrm{mSv})$ through occupational exposure. ${ }^{7}$ This is comparable to the exposure received by workers at nuclear plants, but only slightly higher than the commonly occurring background level of radiation. ${ }^{89}$ Measurements of electromagnetic fields in the aircraft during flight have indicated exposure levels in the order of 2-3 milliGauss (mG) in economy class and 5-10 mG in first class. ${ }^{7}$ Furthermore, it has been suggested that disruption of the circadian rhythm in association with long distance flights may influence melatonin levels, and thereby, increase the risk of certain cancer types. ${ }^{10}$ Other possible causes of an excess risk of breast cancer among female cabin crew concern reproductive factors, including the number of pregnancies and age at birth of first child. ${ }^{1}$

An increased incidence of malignant melanoma and overall cancer in female flight attendants was found in a recent Icelandic study. ${ }^{4}$ The increased incidence of overall cancer and breast cancer was found primarily in cabin crew starting work in 1971 or later. An increased incidence of malignant melanoma, as well as non-melanoma skin cancer, has also recently been reported for Norwegian cabin attendants for both genders. ${ }^{6}$ Among men there was also an increased incidence of cancer in the upper respiratory and gastric tract, and cancer of the liver. A recent study from the United States reported an increased incidence of malignant melanoma in male as well as in female cabin crew. ${ }^{5}$ Studies of cancer incidence in pilots do not give a completely consistent pattern, but indicate that pilots have increased risks of malignant melanoma and non-melanoma skin cancer. ${ }^{11-19}$

The possible excess of breast cancer among female cabin crew and the lack of a consistent pattern in previous epidemiological studies makes it important to provide additional data on the cancer incidence in this group. ${ }^{20}$ In view of different hypotheses of possible agents that may cause an increased risk of cancer, it is also of interest to compare cabin attendants with or without experience of high altitude, long distance flight duty. The aim of this study was to describe the cancer incidence in Swedish cabin crew during the period 1961-96. Total block hours and exposure to high altitude, long distance flights were analysed in relation to cancer incidence in cancer cases and matched controls during 1980-96.

\section{MATERIALS AND METHODS}

The study population consisted of cabin crew employed at the Swedish Scandinavian Airline System (SAS), resident in Sweden and employed some time during the period 1957-94. The cabin attendants at SAS were identified using administrative company registers of employees and archive documents at the Swedish part of SAS. In all, the study population included 3202 subjects. The Swedish personal identification number and date of employment were retrieved for 2956 of the study population (92\%), of whom 2324 were women and 632 men. Analyses of the completeness of the cohort indicated only a small number of cabin crew missing when 
Main messages

- Cabin crew are occupationally exposed to several factors that may be associated with an increased risk of cancer, including cosmic radiation.

- Previous studies have shown an excess risk of breast cancer among female cabin crew. This was given further support in the present study where a nonsignificant increased incidence of breast cancer among Swedish female cabin crew was found.

- An increased incidence of malignant melanoma was seen for cabin crew of both genders, and of nonmelanoma skin cancer for men. This increased incidence may be due to exposure to UV radiation at work or outside work.

compared with information about annual numbers of cabin attendants employed at SAS during the study period.

Incident cases of cancer in the study population during the period 1961-96 were identified by record linkage to the Swedish National Cancer Register using the personal identification number. Similarly, all deaths in the study population during this period were obtained from the National Cause of Death Register. From a register of migration at Statistics Sweden, all migrations into or out of Sweden by members of the study population during the years 1968-96 were recorded. Reproductive history for the female cabin attendants was obtained using the Multi-Generation Register at Statistics Sweden and the National Medical Birth Register. The Multi-Generation Register was also used for information about parity and age at birth of first child among women in Sweden in 1980.

The observation period started on 1 January 1961, at the time of employment or at the time of immigration to Sweden, whichever came last. It ended on 31 December 1996, at the time of death, or at the time of emigration out of Sweden, whichever came first. For a subject moving out of the country, the observation period was terminated at the time of emigration, irrespective of eventual later re-migration to Sweden.

Dates of employment were collected from archives at Swedish SAS. From 1979 onwards, cumulative block hours by aircraft type during employment in Swedish SAS were recorded by the company on a routine basis, yielding monthly summary reports. Block hours include the time from departure of a flight until arrival, in the air as well as on the ground. From these reports cumulative block hours by aircraft type were extracted annually by 31 December during the period 1979-95 for the cancer cases registered from 1980 to 1996 and for four controls per case. The controls were randomly selected from each case's "risk set", which was composed of all individuals in the cohort who matched the case by gender and age group ( \pm 5 years), and who were employed in SAS and not diagnosed with cancer at the time the case was diagnosed. In 1993 a Swedish domestic airline company (Linjeflyg) was merged with Swedish SAS. Cabin crew formerly employed in Linjeflyg could not be included in the case-control study because of a lack of information on block hours before joining Swedish SAS. Information about annual cumulative block hours for the remaining cabin crew was obtained for 48 cases and 174 controls (92\%). For some cabin attendants, however, block hours were missing for one or more years during the observation period, and for these years cumulative block hours were imputed using information from adjacent years. High altitude, long distance flights were determined on the basis of the aircraft type. All block
Policy implications

- Cabin crew have about the same overall cancer incidence as the general Swedish population.

- An increased incidence of malignant melanoma and a possibly increased incidence of breast cancer in female cabin crew need to be further studied with regard to possible causes at work or outside work.

hours attributed to DC 8, DC 10, Boeing 747, and Boeing 767 were considered to concern high altitude, long distance flights.

Information on reproductive factors among the female cabin attendants and among the total Swedish female population in 1980 was used to evaluate to what extent reproductive factors may have influenced the breast cancer incidence of female cabin attendants in the present study. The method used has been recommended when evaluating confounding due to cigarette smoking in occupational studies. ${ }^{21}$ In this evaluation we used estimates from a metaanalysis of the relative risk of breast cancer for the Swedish female population according to reproductive factors. ${ }^{22}$

\section{Statistical analyses}

Cancer incidence overall and for specific cancer sites for cabin crew were compared with the corresponding incidence in the general Swedish population by calculation of standardised incidence ratios (SIR), based on the ratio of the observed number of cases and the expected number of cases. The expected number of cases was computed using five-year age groups and eight different calendar periods (1961-62, 196367, 1968-72, 1973-77, 1978-82, 1983-87, 1988-92, 1993-96). Together with the SIR, 95\% confidence intervals (95\% CI) were computed, assuming that the observed number of cancer cases followed a Poisson distribution. The case-control study nested within the cohort was analysed by calculating odds ratios (OR) for cancer incidence overall, malignant melanoma, and for breast cancer among women by comparing cabin crew with at least 10000 cumulated block hours, any high altitude, long distance flight duty, and cabin crew with at least 5000 high altitude, long distance flight hours with cabin attendants without this experience. Odds ratios were calculated, together with 95\% confidence intervals, using conditional logistic regression. Analyses were carried out using Epicure (HiroSoft, Seattle, WA) and SAS for Windows, version 8 .

\section{RESULTS}

The total number of person-years was 39135 in women, and 12774 in men. At the start of follow up, members of the cabin crew were in general below 30 years of age; a dominant part of the person-years generated in this study were below 50 years of age. Only about 5\% of the person-years were above 60 years of age, which is the regular age of retirement among cabin crew in Sweden. Emigration and immigration was quite common in the cohort; $21.1 \%(n=490)$ of the women emigrated during the study period and $5.3 \%$ $(n=124)$ immigrated. The corresponding figures for men were $19 \%(n=120)$ emigrants and $8.5 \%(n=54)$ immigrants. At the end of follow up 29 women and 48 men were dead.

A total of 109 cancer cases were observed, of which 76 were among women and 33 among men. The observed number of cases was close to that expected on the basis of the cancer incidence of the general Swedish population, taking age and calendar period into consideration (table 1). The SIR was 1.01 
Table 1 Cancer incidence 1961-96 among cabin crew at the Swedish SAS compared to the general Swedish population

\begin{tabular}{|c|c|c|c|c|c|c|c|c|}
\hline \multirow[b]{2}{*}{ Cancer site (ICD-7 code) } & \multicolumn{4}{|c|}{ Women } & \multicolumn{4}{|c|}{ Men } \\
\hline & O* & E† & SIR $\ddagger$ & $95 \% \mathrm{Cl}$ & $0^{*}$ & E† & SIR $\ddagger$ & $95 \% \mathrm{Cl}$ \\
\hline All cancer (140-207) & 76 & 75.27 & 1.01 & 0.78 to 1.24 & 33 & 28.54 & 1.16 & 0.76 to 1.55 \\
\hline Colon (153) & 1 & 3.05 & 0.33 & 0.01 to 1.83 & 3 & 1.87 & 1.61 & 0.33 to 4.70 \\
\hline Rectum (154) & 2 & 1.68 & 1.19 & 0.14 to 4.29 & 1 & 1.33 & 0.75 & 0.02 to 4.18 \\
\hline Pancreas (157) & 2 & 0.89 & 2.24 & 0.27 to 8.08 & 0 & 0.81 & - & 0.00 to 4.57 \\
\hline Lung (162) & 3 & 2.70 & 1.11 & 0.23 to 3.24 & 2 & 2.97 & 0.67 & 0.08 to 2.43 \\
\hline Breast (170) & 33 & 25.45 & 1.30 & 0.85 to 1.74 & 0 & 0.05 & - & 0.00 to 71.74 \\
\hline Cervix uteri (171) & 4 & 5.67 & 0.70 & 0.19 to 1.81 & - & - & - & - \\
\hline Corpus uteri (172) & 2 & 3.22 & 0.62 & 0.08 to 2.25 & - & - & - & - \\
\hline Ovary (175) & 2 & 4.78 & 0.42 & 0.05 to 1.51 & - & - & - & - \\
\hline Prostate (177) & - & - & - & - & 2 & 4.20 & 0.48 & 0.06 to 1.72 \\
\hline Kidney (180) & 2 & 1.20 & 1.67 & 0.20 to 6.04 & 0 & 1.28 & - & 0.00 to 2.89 \\
\hline Urinary bladder (181) & 0 & 0.94 & - & 0.00 to 3.90 & 4 & 1.98 & 2.02 & 0.55 to 5.18 \\
\hline Malignant melanoma of the skin (190) & 11 & 5.04 & 2.18 & 1.09 to 3.90 & 6 & 1.64 & 3.66 & 1.34 to 7.97 \\
\hline Head and neck (190.0-190.4) & 1 & 0.31 & 3.24 & 0.08 to 18.04 & 1 & 0.17 & 6.05 & 0.15 to 33.72 \\
\hline Trunk (190.5) & 7 & 1.57 & 4.46 & 1.79 to 9.19 & 5 & 0.86 & 5.82 & 1.89 to 13.57 \\
\hline Limbs (190.6-190.7) & 3 & 2.78 & 1.08 & 0.22 to 3.16 & 0 & 0.45 & - & 0.00 to 8.22 \\
\hline Non-melanoma skin (191)§ & 0 & 0.85 & - & 0.00 to 4.35 & 4 & 0.90 & 4.42 & 1.20 to 11.32 \\
\hline Kaposi's sarcoma (191 \& pad 505) & 0 & 0.01 & - & 0.00 to 537.76 & 1 & 0.01 & 105.33 & 2.63 to 586.90 \\
\hline Brain and nervous system (193) & 4 & 3.82 & 1.05 & 0.29 to 2.68 & 1 & 1.54 & 0.65 & 0.02 to 3.63 \\
\hline Unspecified sites (199) & 1 & 1.46 & 0.68 & 0.02 to 3.80 & 3 & 0.89 & 3.38 & 0.70 to 9.88 \\
\hline Leukaemia (204-207) & 4 & 1.27 & 3.14 & 0.86 to 8.04 & 1 & 0.85 & 1.17 & 0.03 to 6.54 \\
\hline \multicolumn{9}{|c|}{$\begin{array}{l}\text { Cancer sites with less than two observed cases are not shown in the table. } \\
\text { *Observed number of cases. } \\
\text { †Expected number of cases, taking age and calendar period into consideration. } \\
\text { †SIR, standardised incidence ratio. } \\
\S \text { Basal cell carcinoma is not included since this diagnosis was not reported to the National Cancer Register. }\end{array}$} \\
\hline
\end{tabular}

(95\% CI 0.78 to 1.24 ) for women and 1.16 (95\% CI 0.76 to 1.55) for men. In both genders there was an increased incidence of malignant melanoma (SIR 2.18 (95\% CI 1.09 to 3.90) for women and 3.66 (95\% CI 1.34 to 7.97 ) for men). Men also showed an increased incidence of non-melanoma skin cancer (SIR 4.42; 95\% CI 1.20 to 11.32). Of the four cases of non-melanoma skin cancer in men, one was a Kaposi's sarcoma, which, because of the very low incidence in the general population, gave a high SIR. In women, a nonsignificant increased incidence was found for breast cancer (SIR 1.30; 95\% CI 0.85 to 1.74) and for leukaemia (SIR 3.14; 95\% CI 0.86 to 8.04 ).

No clear associations were found between years of employment and cancer incidence overall or malignant melanoma, nor for breast cancer among women (table 2). For malignant melanoma the total number of observed cases for men and women combined was 17 compared to 6.53 expected (SIR 2.61; 95\% CI 1.52 to 4.17; not shown in table). Based on these 17 cases no association with length of employment was seen. The SIR for malignant melanoma was in the order of 2.2-3.0 throughout the study period with no substantial changes. An increased incidence of leukaemia was seen among subjects with 20 or more years of employment in SAS, but this was based on only two cases (not shown in table).

Information about total flight hours and flight hours in high altitude, long distance flights was obtained for 48 cancer cases diagnosed 1980-96 and for 174 controls. Of these cases 16 had breast cancer and 10 melanoma or non-melanoma skin cancer. The numbers of total and high altitude, long distance block hours, respectively, were similar between cases and controls. There were substantial differences in block hours between men and women. The average number of total cumulative block hours in 1995 was 6440 hours for female and 13370 hours for male cabin crew. In general, no statistically significant associations between block hours and/or experience of high altitude, long distance flights and cancer incidence could be determined. In most analyses, the number of cases was small (table 3). Female cabin crew with at least 5000 high altitude, long distance block hours showed a non-significant increased incidence for breast cancer (SIR 3.27; $95 \%$ CI 0.54 to 19.70 ) compared to female cabin crew

Table 2 Cancer incidence 1961-96 among cabin attendants at Swedish SAS compared to the general Swedish population

\begin{tabular}{|c|c|c|c|c|c|c|c|c|c|}
\hline \multirow[b]{2}{*}{ Cancer site } & \multirow{2}{*}{$\begin{array}{l}\text { Employment } \\
\text { years in SAS }\end{array}$} & \multicolumn{4}{|c|}{ Women } & \multicolumn{4}{|c|}{ Men } \\
\hline & & $\mathrm{O}^{*}$ & E† & SIR $\ddagger$ & $95 \% \mathrm{Cl}$ & $\mathrm{O}^{*}$ & $\mathrm{E} \dagger$ & SIR $\ddagger$ & $95 \% \mathrm{Cl}$ \\
\hline \multirow[t]{3}{*}{ All cancer } & $<10$ & 35 & 31.48 & 1.11 & 0.74 to 1.48 & 9 & 6.66 & 1.35 & 0.62 to 2.56 \\
\hline & $10-19$ & 24 & 29.91 & 0.80 & 0.48 to 1.12 & 7 & 6.91 & 1.01 & 0.41 to 2.09 \\
\hline & 20 & 14 & 12.19 & 1.15 & 0.63 to 1.93 & 16 & 13.51 & 1.18 & 0.68 to 1.92 \\
\hline \multirow[t]{3}{*}{ Breast cancer } & $<10$ & 13 & 9.56 & 1.36 & 0.72 to 2.32 & - & - & - & - \\
\hline & $10-19$ & 13 & 10.32 & 1.26 & 0.67 to 2.15 & - & - & - & - \\
\hline & 20 & 7 & 5.04 & 1.39 & 0.56 to 2.86 & - & - & - & - \\
\hline \multirow[t]{3}{*}{ Malignant melanoma } & $<10$ & 6 & 2.45 & 2.45 & 0.90 to 5.33 & 2 & 0.48 & 4.15 & 0.50 to 14.98 \\
\hline & $10-19$ & 2 & 1.86 & 1.08 & 0.13 to 3.89 & 3 & 0.46 & 6.59 & 1.36 to 19.25 \\
\hline & 20 & 3 & 0.65 & 4.60 & 0.95 to 13.44 & 1 & 0.63 & 1.59 & 0.04 to 8.86 \\
\hline
\end{tabular}

*Observed number of cases.

tExpected number of cases, taking age and calendar period into consideration.

¥SIR, standardised incidence ratio. 
Table 3 Relative risk (odds ratio; OR) of certain cancer sites in relation to flight hours and high altitude, long distance flight duty among cabin crew

\begin{tabular}{|c|c|c|c|c|c|c|c|c|c|}
\hline \multirow[b]{2}{*}{ Cancer site } & \multicolumn{3}{|c|}{$>10000$ total block hours } & \multicolumn{3}{|c|}{ High altitude, long distance flight duty } & \multicolumn{3}{|c|}{$\begin{array}{l}>5000 \text { block hours in high altitude, long } \\
\text { distance flights }\end{array}$} \\
\hline & Cases & OR & $95 \% \mathrm{Cl}$ & Cases & OR & $95 \% \mathrm{Cl}$ & Cases & OR & $95 \% \mathrm{Cl}$ \\
\hline \multicolumn{10}{|l|}{ Women } \\
\hline All cancer & 7 & 1.68 & 0.41 to 6.83 & 26 & 1.43 & 0.40 to 5.04 & 7 & 1.31 & 0.44 to 3.86 \\
\hline Breast & 3 & 1.14 & 0.15 to 8.48 & 14 & 1.79 & 0.31 to 10.45 & 5 & 3.27 & 0.54 to 19.70 \\
\hline Malignant melanoma & 2 & 2.67 & 0.20 to 35.14 & 5 & $-^{*}$ & - & 2 & 2.59 & 0.18 to 37.20 \\
\hline \multicolumn{10}{|l|}{ Men } \\
\hline All cancer & 14 & 3.60 & 0.28 to 46.32 & 17 & $-^{*}$ & - & 13 & 0.21 & 0.04 to 1.28 \\
\hline Malignant melanoma & 3 & $-^{*}$ & - & 5 & $-^{*}$ & - & 3 & 1.00 & 0.03 to 31.97 \\
\hline \multicolumn{10}{|l|}{ All cabin crew } \\
\hline All cancer & 21 & 2.03 & 0.60 to 6.90 & 43 & 1.29 & 0.39 to 4.29 & 20 & 0.78 & 0.30 to 2.05 \\
\hline Malignant melanoma & 5 & 4.67 & 0.45 to 49.14 & 10 & $-^{*}$ & - & 5 & 1.83 & 0.23 to 14.52 \\
\hline
\end{tabular}

with less or no experience of high altitude, long distance flights.

The proportion of the female cabin attendants who had given birth to a child was $72.5 \%$, which was very close to the corresponding proportion among all Swedish women in 1980 (table 4). Female cabin attendants tended to have fewer pregnancies, which were later in life. The proportion of cabin attendants who gave birth before 25 years of age was only $7 \%$ compared to $51 \%$ among all Swedish women. Given these differences in reproductive history and with the relative risks for breast cancer, estimated from a Nordic meta-analysis, ${ }^{22}$ one could expect an excess incidence of breast cancer among female cabin crew in the order of $10 \%$ (SIR 1.10) compared to the Swedish female population. This is lower than, but considering random variation, consistent with, the observed SIR for breast cancer in this study.

\section{DISCUSSION}

The results of the present study showed an increased incidence of malignant melanoma in Swedish cabin crew among both men and women and of non-melanoma skin cancer in men. These increased incidences are in agreement with corresponding analyses previously reported from Iceland, Norway, and the United States ${ }^{4-6}$; similar findings have also been suggested from studies of Nordic pilots. ${ }^{15-18}$ The increased incidence of malignant melanoma remained stable throughout the study period. During this period the incidence of malignant melanoma increased in the population, ${ }^{23}$ which with stable relative risks for cabin crew would mean a greater increase of the incidence among cabin attendants than in the general population. The non-significantly increased incidence of breast cancer in female cabin crew is consistent with the previously reported corresponding results from Iceland, Finland, and the United States, but at variance with the results from a Norwegian study. ${ }^{14-6}$

The Swedish National Cancer Register used in this study for identification of cases is based on a compulsory reporting of diagnosed cases and has a high degree of completeness. A comparison to the National Cause of Death Register in 1978 showed a loss of cases in the Cancer Register of $4.5 \% .{ }^{24}$ Each case is generally reported both by the clinician first making the diagnosis and also by a pathologist or cytologist. This contributes to a comparatively low misclassification of disease in the cancer register. It is possible that the frequent and regular health examinations of the cabin attendants contributes to an earlier detection of cancer cases and thus to a higher diagnostic rate. This could result in an overestimation of the cancer incidence in cabin crew compared with the general population.

Cabin crew is an occupational group with a comparatively extensive international migration. In this study we could take immigration to and emigration from Sweden into account by using national population registers going back to 1968. In order to avoid a loss of cases due to immigration or emigration, the follow up time was started at the time of immigration and terminated at the time of first emigration. Thus, no person-time at risk was accumulated outside Sweden, where cancer cases could not be detected. The loss of person-years and cases among subjects returning to Sweden was about $10 \%$ of all potential person-years and cases in the study. By record linkage to the National Cause of

Table 4 Reproductive factors in the Swedish population (1980) and in the female cabin crew (1946-96) together with estimates from a Nordic meta-analysis of relative risk of breast cancer due to reproductive factors ${ }^{22}$

\begin{tabular}{|c|c|c|c|c|c|}
\hline \multirow[b]{2}{*}{ Reproductive factors } & \multirow[b]{2}{*}{$\mathrm{RR}^{*}$} & \multicolumn{2}{|l|}{ Population } & \multicolumn{2}{|c|}{ Cabin crew } \\
\hline & & No. & $\%$ & No. & $\%$ \\
\hline \multicolumn{6}{|l|}{ Parity } \\
\hline Parous & 1.00 & 2178139 & 73.2 & 1685 & 72.5 \\
\hline Nulliparous & 1.29 & 796077 & 26.8 & 639 & 27.5 \\
\hline \multicolumn{6}{|l|}{ Number of children } \\
\hline $1-2$ & 1.00 & 1549831 & 71.1 & 1314 & 78.0 \\
\hline $3-4$ & 0.84 & 546197 & 25.1 & 363 & 21.5 \\
\hline 5 or more & 0.69 & 82111 & 3.8 & 8 & 0.5 \\
\hline \multicolumn{6}{|c|}{ Age at birth of first child (y) } \\
\hline$<20$ & 1.00 & 261719 & 12.0 & 11 & 0.6 \\
\hline $20-24$ & 1.04 & 850064 & 39.0 & 113 & 6.7 \\
\hline $25-29$ & 1.17 & 655973 & 30.1 & 748 & 44.4 \\
\hline $30-34$ & 1.30 & 277152 & 12.8 & 623 & 37.0 \\
\hline$>34$ & 1.40 & 133231 & 6.1 & 190 & 11.3 \\
\hline
\end{tabular}

*Relative risks associated with reproductive factors in the Nordic countries. ${ }^{22}$ 
Death Register, all deaths during the study period could be obtained, thereby avoiding an overestimation of the personyears at risk.

Total block hours and block hours at high altitude, long distance flights were estimated from monthly reports recorded at the Swedish SAS. This does not give a complete account of all block hours of the cohort members. In particular, block hours obtained in service for other companies would be underrepresented or completely missing. This would contribute to a misclassification of block hours, probably underestimating total exposure and exposure to high altitude, long distance flights. It is possible that this has contributed to the lack of association between total block hours and high altitude, long distance block hours, respectively, and cancer incidence in this study. This source of error cannot, however, explain the associations or lack of associations seen in analyses of all cabin crew, irrespective of classification according to block hours or aircraft type. Information about block hours was only available from 1979 and onwards. In analyses of exposure to high altitude, long distance flights the numbers of cases was often small. Since the flight duty of cabin attendants in Sweden during the 1960s and 1970s mostly concerned propeller planes flying at lower altitudes it is unlikely that inclusion of these earlier years would have substantially increased the number of cases exposed to high altitude, long distance flights.

It is likely that the observed increase of malignant melanoma of the skin in all cabin crew and of non-melanoma skin cancer in male cabin crew is real. The causes of these increased risks remain unclear, and both occupational and non-occupational causes may be involved. The melanomas often occurred on the trunk, indicating that sunburn could be of aetiological importance. Measurements of UV radiation in the aircraft during flight have shown very low levels of exposure, and that the windshield of the aircraft gives a good protection against this type of radiation. ${ }^{25}$ Thus, work as a cabin attendant during flight does not seem to give an increase in exposure to UV radiation.

We observed a non-significant increased incidence of breast cancer in female cabin crew. In view of similar findings in other Nordic countries and in the United States it is likely that this reflects a real increased incidence in this occupational group. The causes of this increase are not known and may involve occupational as well as other factors, including reproductive history. We estimated that the reproductive history in female cabin crew could yield a $10 \%$ increase in breast cancer incidence compared to the general population. This could be an important contributing factor to the increased breast cancer incidence in female cabin crew, but does not seem to fully explain this excess. It has been suggested that exposure to cosmic ionising radiation and disturbances of the circadian rhythm at long distance flights may be causes of an increased risk of breast cancer in cabin crew. Our findings in analyses of block hours and high altitude, long distance flights are consistent with these hypotheses, but the numbers were small and the results therefore uncertain. Analysis of employment years in SAS indicated that the breast cancer risk was similar regardless of the number of working years. However, some cabin crew may have been working as cabin attendants for other companies during their career. Our results, together with those of previous studies, call for further investigations of breast cancer risk in female cabin crew.

\section{ACKNOWLEDGEMENTS}

We thank Tor Haldorsen for excellently introducing us to the Epicure software; Per Olsson, Gunilla Hofvander, Charlotte Nilsson, Carina Nordén, Eva Gustafsson, and Vesna Sternung for assistance with data collection; Per-Olof Nygren, Anita Lysén, Signe MildeKolmskog, and Eva Helderud at SAS General and Management Archives, Stockholm; and SAS Human Resources, Sweden.

Evaluated and approved by the Ethical Committee of Karolinska Institutet, diary number 99-391. Supported by grant no. 2001-0198 from the Swedish Council for Work Life Research.

\section{Authors' affiliations}

A Linnersjö, Department of Epidemiology, Stockholm Center of Public Health, Stockholm, Sweden

N Hammar, Department of Epidemiology, Institute of Environmental Medicine, Karolinska Institutet, and Department of Epidemiology, Stockholm Center of Public Health, Stockholm, Sweden

B-G Dammström, M Johansson, Swedish SAS, Stockholm, Sweden H Eliasch, Flight Medical Center, Swedish Air Force, and Swedish SAS, Stockholm, Sweden

\section{REFERENCES}

1 Pukkala $E$, Auvinen A, Wahlberg G. Incidence of cancer among Finnish airline cabin attendants, 1967-92. BMJ 1995;311:649-52.

2 Lynge $\mathbf{E}$. Risk of breast cancer is also increased among Danish female airline cabin attendants. BMJ 1996;312:253.

3 Wartenberg D, Stapleton CP. Risk of breast cancer is also increased among retired US female airline cabin attendants. BMJ 1998;316:1902.

4 Rafnsson V, Tulinius H, Jónasson JG, et al. Risk of breast cancer in female flight attendants: a population-based study (Iceland). Cancer Causes Control 2001;12:95-101.

5 Reynolds P, Cone J, Layefsky M, et al. Cancer incidence in California flight attendants (United States). Cancer Causes Control 2002;13:317-24.

6 Haldorsen T, Reitan JB, Tveten U. Cancer incidence among Norwegian airline cabin attendants. Int J Epidemiol 2001;30:825-30.

7 Nicholas JS, Lackland DT, Butler GC, et al. Cosmic radiation and magnetic field exposure to airline flight crews. Am J Ind Med 1998;34:574-80.

8 Blettner M, Grosche B, Zeeb H. Occupational cancer risk in pilots and flight attendants: current epidemiological knowledge. Radiat Environ Biophys 1998:37:75-80.

9 Swedish Radiation Protection Authority. Fakta om strålning. Naturlig strålning. [ssi.se Online] [Accessed 18 September 2002]. Available at www.ssi.se/fakta_om stroelning/Stroelningsbroschyr/Naturlig str.htm

10 Mawson AR. Breast cancer in female flight attendants. Lancet 1998;352:626.

11 Band PR, Spinelli JJ, Ng VT, et al. Mortality and cancer incidence in a cohort of commercial airline pilots. Aviat Space Environ Med 1990;61:299-302.

12 Band PR, Le ND, Fang R, et al. Cohort study of Air Canada pilots: mortality, cancer incidence, and leukaemia risk. Am J Epidemiol 1996;143:137-43.

13 Grayson JK, Lyons TJ. Cancer incidence in United States air force aircrew, 1975-89. Aviat Space Environ Med 1996;67:101-4.

14 Grayson JK. Radiation exposure, socioeconomic status and brain tumor risk in the US Air Force: a nested case-control study. Am J Epidemiol 1996:143:480-6.

15 Gundestrup M, Storm HH. Radiation-induced acute myeloid leukaemia and other cancers in commercial jet cockpit crew: a population-based cohort study. Lancet 1999;354:2029-31.

16 Haldorsen T, Reitan JB, Tveten U. Cancer incidence among Norwegian airline pilots. Scand J Work Environ Health 2000;26:106-11.

17 Rafnsson V, Hrafnkelsson J, Tulinius H. Incidence of cancer among commercial airline pilots. Occup Environ Med 2000;57:175-9.

18 Hammar $\mathrm{N}$, Linnersjö A, Eliasch $\mathrm{H}$, et al. Cancer incidence in airline and military pilots in Sweden 1961-1996. Aviat Space Environ Med 2002;73:2-7.

19 Milanov L, Dimitrov D, Danon S. Cancer incidence in republic of Bulgaria aircrew, 1964-1994. Aviat Space Environ Med 1999;70:681-5.

20 Lynge E. Commentary: Cancer in the air. Int J Epidemiol 2001;30:830-2.

21 Axelson $\mathrm{O}$, Steenland K. Indirect methods of assessing the effects of tobacco use in occupational studies. Am J Ind Med 1988;13:105-18.

22 Ewertz M, Duffy SW, Adami HO, et al. Age at first birth, parity and risk of breast cancer: a meta-analysis of 8 studies from the Nordic Countries. Int J Cancer 1990:46:597-603.

23 Westerdahl J. Malignant melanoma-risk factors. Thesis. Lund, Sweden: Lund University, 1995

24 Mattsson B, Wallgren A. Completeness of the Swedish Cancer Register. Nonnotified cancer cases recorded on death certificates in 1978. Acta Radiol Oncol 1984:23:305-13.

25 Diffey BL, Roscoe AH. Exposure to solar ultraviolet radiation in flight. Aviat Space Environ Med 1990;61:1032-5. 